\title{
Ovarian Seromucinous Cystadenoma
}

National Cancer Institute

\section{Source}

National Cancer Institute. Ovarian Seromucinous Cystadenoma. NCI Thesaurus. Code C126310.

A non-metastasizing cystic mixed epithelial neoplasm that arises from the ovary. It is characterized by the presence of more than one epithelial cell type, most often serous and endocervical-type mucinous. 